\title{
Virtual Reality (VR) as a Source for Self-Efficacy in Teacher Training
}

\author{
Yonit Nissim $^{1} \&$ Eyal Weissblueth ${ }^{1}$ \\ ${ }^{1}$ School of Education, Ohalo Academic College, Israel \\ Correspondence: Eyal Weissvlueth, School of Education, Ohalo Academic College, Qatzrin 12900, Israel. Tel: \\ 972-4-682-5012. E-mail: eyalw@ohalo.ac.il
}

Received: February 19, 2017

doi:10.5539/ies.v10n8p52

\author{
Accepted: March 20, 2017 \\ Online Published: July 29, 2017 \\ URL: https://doi.org/10.5539/ies.v10n8p52
}

\begin{abstract}
The current study sought to explore the experiences of pre-service student teachers in a teaching unit in VR within a special course framework which was intended to enhance student-teacher's $21^{\text {st }}$ century skills and growth processes. In particular, how their experiences working with VR affected their self-efficacy. The research population comprised of 176 students studying in their second of a four years training course to become teachers in the K-12 educational system. The main research question was: Do teaching approaches employing VR effect student teachers' self-efficacy, interests, and creativity? If so, what are these effects? How does collaboration in VR classroom foster learners' social integration? The main findings of this study showed that using VR learning environments with student teachers helped them increase their self-efficacy and allowed them to be more innovative and creative. VR challenges learners with active teaching and learning, making student teachers active participants who create and innovate.
\end{abstract}

Keywords: virtual reality, self-efficacy, teachers, emotions, creativity

\section{Introduction}

\subsection{In General}

In modern world, education and technology are interconnected, which are both significant parts of daily life. Using technology in education makes learning and teaching more meaningful, advanced, and future-oriented. VR is increasingly used as an educational mode of learning and teaching with a purpose of enriching learning processes. It stimulates interest and enhances the concentration of students by teaching through otherwise impossible experiences, allowing the use of experimental tools, presented as virtual objects, directly to their hands (Ahn \& Cho, 2015).

The literature is rich with descriptions of the successes of student teachers whose teachers constructed their lessons with educational themes that were congruent with the new subject matter related to their academic disciplines (Nissim, Weissblueth, Scott-Webber, \& Amar, 2016; Weissblueth, Nissim, \& Amar, 2014). Among educational themes lies VR. However, VR in education lacks research and requires a pedagogical examination of situations where students can be involved with educational creations. The current study sought to shed light on the personal and pedagogical effect of using VR on pre service student teachers.

VR enables teachers, lecturers, or anyone in an educational setting to devise and deliver complex information in a visually attractive way. There is a tendency to think that many students find it easier to learn when presented with a visual explanation, one that they also find easier to retain and recall. Chen (2006) asserted that: "although VR is recognized as an impressive learning tool, there are still many issues that need further investigation, including identifying the appropriate theories and/or models to guide its design and development, investigating how its attributes are able to support learning, finding out whether its use can improve the intended performance and understanding, investigating ways to reach more effective learning when using this technology, and investigating its impact on learners with different aptitudes".

Her research resulted in insights on a feasible instructional design theoretical framework, as well as an instructional development framework for VR based learning environments (Chen, 2006).

Pantelidis (2010) suggested that VR motivates students. It does so by requiring interaction and encouraging active rather than passive participation. Some types of VR encourage or require collaboration and provide a social atmosphere to support it. For example, using text input in virtual worlds. VR allows the learner to proceed 
through an experience at their own pace, over a broad time scale that is not fixed by a regular class schedule. It allows the disabled to participate in an experiment or learning environment when they cannot do so otherwise. It transcends language barriers. VR with text access provides equal opportunity for communication with students in other cultures and allows the student to take on the role of a person in different cultures (Kim \& Ko, 2012).

Thus, VR creates a virtual world to teach experientially about the real world whether in the past, present or future. It is a significant learning program which surpasses the conventional learning class boundaries, place and space. For the purposes of structured learning space, it allows ample room for creativity and almost boundless learning possibilities. One goal of VR in an educational setting is to make the learning environment of VR - a learning lab, another classroom online, and a learning method empowering abilities, learning skills, and creativity (Kim \& Ko, 2012).

\subsection{VR, Emotions and Self Efficacy}

Several recent studies showed an association between emotions and VR. Good VR acts as an emotional amplifier. This process is most easily demonstrated with emotions that can be intensified: i.e. happiness, sadness, awe, curiosity, pride, and even emotional attachments to other characters. All of these are likely to be much stronger when executed well in VR. Moreover, this ability to create strong emotions also makes VR ideal for education and learning.

Emotions play a significant role in a teachers' work. Teachers are regularly required to deal with situations involving emotions, and it is therefore very important to develop and nurture their emotional abilities (Kremenitzer \& Miller, 2008). Although emotions are an integral part of the teacher's work having an impact on behavior and motivation, as well as influence on the effectiveness of teaching, only a limited number of studies have been carried out in the field (Sutton \& Wheatley, 2003). Developing and nurturing emotional intelligence among teachers in general, and younger teachers especially, could be accomplished using different tools. These tools can increase awareness of the components of emotional intelligence and allow teachers to be more conscious of what is happening to themselves and to their students. Increasing teachers' self-awareness may also develop the awareness and emotional intelligence of their students as well (Kremenitzer \& Miller, 2008). Although the teacher's training framework is designed to inculcate and foster teaching skills, a teacher's success also depends on personal abilities and sensitivity. Thus, introducing awareness of emotional intelligence components helps develop these skills (Cherniss, 2000). Self-efficacy beliefs are an important factor in human motivation and behavior, and in influencing emotion and action. Self-Efficacy theory holds that performance and motivation are determined, in part, by how effective people believe they can be (Bandura, 1982). Bandura (1995) explained that it "refers to explanation required to manage prospective situations." The most important component of self-efficacy is a person's self-belief in their capabilities (Snyder \& Lopez, 2001), it is a task-specific version of self-esteem (Lunenburg, 2011), and its basic principle is that individuals are more likely to engage in activities for which they have a higher level and less likely to engage in those for which they lower ones (van der Bijl \& Shortridge-Baggett, 2001). It influences people's learning abilities, their motivation, and their performance, as people will often attempt to learn and perform only those tasks in which they believe they will be successful (Lunenburg, 2011).

Self-efficacy among teachers has been the focus of several studies in recent years. Most studies indicated that teachers with high-efficacy are better at teaching (Bautista \& Boone, 2015). Several studies described the extensive use of VR as a therapeutic tool or as an element of self-efficacy empowerment.

Most of these studies are based on Gist \& Mitchell's (1992) theory. Their model consists of four distinct factors that contribute to the increase and empowerment of students' self-efficacy. These factors include the following aspects: physiological arousal, verbal persuasion, vicarious experience, and enactive mastery. Their model and theory were formed within a psychological framework prior to the information technology revolution. We therefore wanted to test this theory in a learning environment using VR. The current investigation was based on the emotional aspects of student teachers during training in the construction of a $3 \mathrm{D}$ educational creation in a VR learning environment.

\subsection{Research Questions}

1) Did teaching using VR have any effects on student teacher interests and creativity? If so, what were these effects?

2) Did teaching using VR have any effect on the self-efficacy of pre-service student teachers? If so, what were these effects? 


\subsection{Research Hypotheses}

We speculated that students' self efficacy will increase after they experience working in VR. We expected them to experience difficulties and a range of emotions in fulfilling the tasks assigned to them, and ultimately succeed. We surmised that this would generate an increase in their self efficacy and stimulate an interest in VR.

\section{Method}

\subsection{Research Population}

One hundred and seventy-six students in second of four-year training period to become teachers in K-12 educational system. Table 1 presents students' distribution by their disciplines and teaching level.

Table 1. Research population distribution (absolute numbers) by their disciplines and teaching level

\begin{tabular}{cccccc}
\hline Grades of teaching & Sciences and Math & Liberal Arts & Special Education & Physical Education & Total \\
\hline K & -- & 52 & 5 & -- & 57 \\
\hline $1-6$ & 7 & 37 & 9 & \multirow{2}{*}{49} & 119 \\
\hline $7-12$ & 16 & & 1 & & \\
\hline
\end{tabular}

\subsection{Research Tools}

VR platform was based on Open Simulator Diva distro (0.8.2.1) installed on i5 Intel $2.2 \mathrm{MHz}, 16 \mathrm{~Gb}$ RAM. The platform built a virtual world (Figure 1) that allowed up to 20 avatars to work simultaneously prior to noticing delay in avatar movements.

Free reflections written by students at the end of the assignment were analyzed qualitatively to extract main themes.

\subsection{Process}

A qualitative research methodology was used based on reflective narrative reports written by 176 pre-service student teachers. Students participated in a course designed to enhance their $21^{\text {st }}$ century skills, preparing them for educational field work in their schools. The 8 semester hours course aimed at enhancing the professional growth processes of student-teachers. This was described elsewhere (Weissblueth et al., 2014).

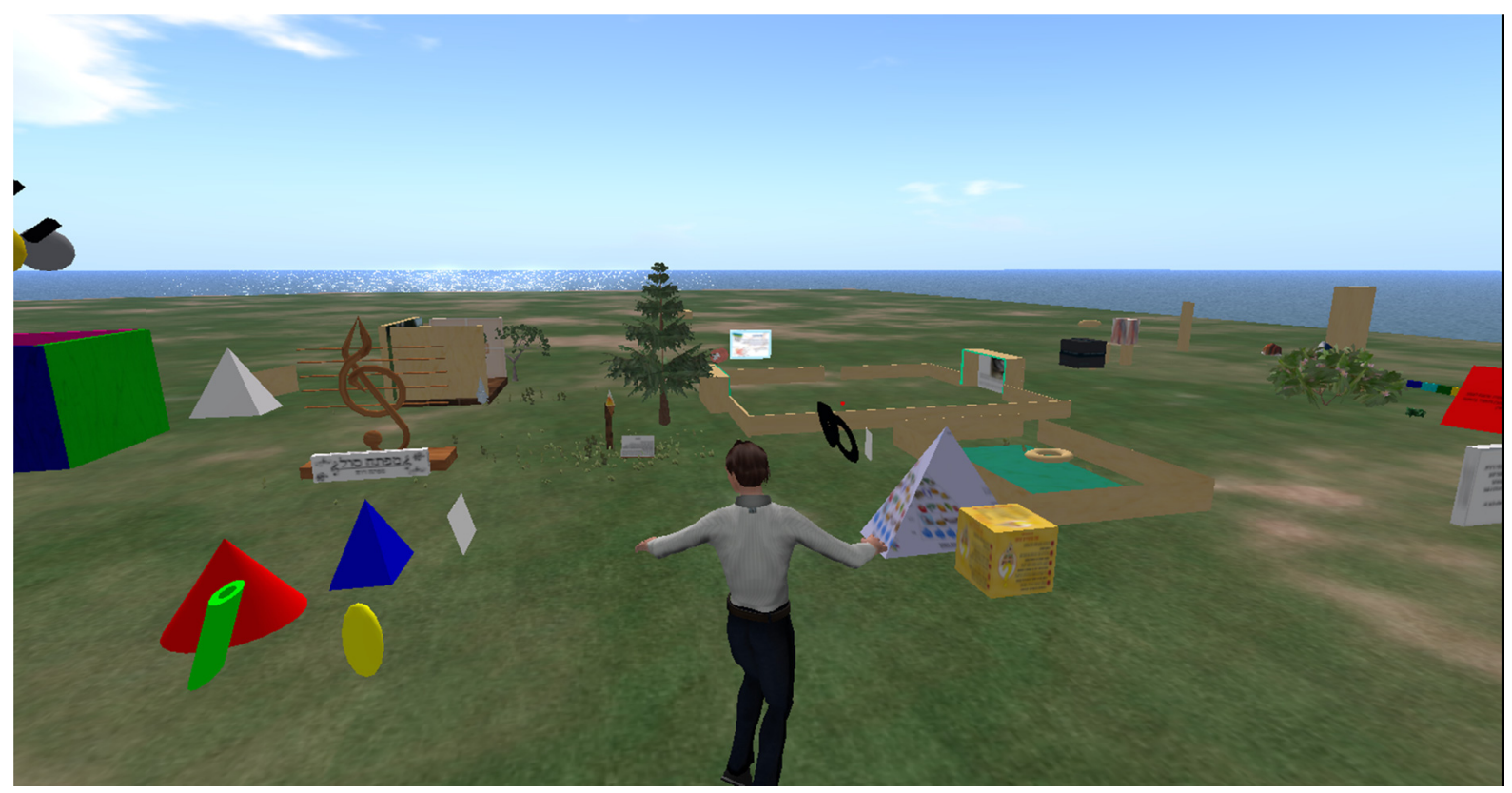

Figure 1. The college's virtual world in which students produced their 3D educational VR creations. Every object appearing in the figure was created by students and accompanied with an explanation of its importance with the purpose of learning how to harness VR Open Simulator platform in the educational arena 
The course introduced a learning module that required students to construct a $3 \mathrm{D}$ educational creation in a VR environment. In doing so, it required them to be creative, to teach and learn online, to collaborate with their peers, to develop problem solving strategies, and to cope with unfamiliar and sometimes complicated technical situations while producing a 3D educational structure in a VR world (see Figure 1).

\subsection{Analysis}

Qualitative narrative analysis was used in three phases (Miles, Huberman, \& Saldaña, 2013). The first phase included sorting and analysis. In this phase coding was used to create concise descriptor labels. The second phase included code sorting and analysis to promote categorization and creation of themes. The third phase included the interpretation of the results while comparing it to the research hypotheses and model of self efficacy increase (Gist \& Mitchell, 1992).

\section{Results}

Upon analyzing the reflections of 176 students and summing them up, several main themes arose:

$\checkmark \quad$ Learning processes became more entertaining.

$\checkmark \quad$ Better understanding and use of technology and VR in teaching.

$\checkmark$ Better development of creative learning and creativity in teaching.

$\checkmark \quad$ More interest in technology.

$\checkmark$ Increased problem solving skills.

$\checkmark \quad$ Increased stamina and endurance in learning.

$\checkmark \quad$ Increased ability to associate what was learned with real life.

Some themes followed the classical model of factors contributing to an increase in self-efficacy (Gist \& Mitchell, 1992). The translated authentic expressions were kept in its original form.

\subsection{Physiological Arousal (Emotional Arousal)}

Students experienced difficulties. They were bothered by the requirement to work on an educational 3D creation in VR, and they even gave up on ideas they thought to be good. For example:

"After many hours I gave up and abandoned the idea. The idea bothered me because my thoughts were dispersed."

However,

“... after consulting, I took a pen and paper and began to write down everything that came to mind...brainstorming helped me a lot to pick a direction."

In this reflection, we can see in a single paragraph describing an emotional thought process which passes from negative frustration to the good feelings of efficacy and empowerment. Other students enjoyed their work and commented that they went through a transition, from being concerned to being enabled, as seen in the following excerpt:

"I felt very good during this process and it was relatively nice. To be frank, I had many concerns about the first assignment. After all, this is a learning process based on complex technology, a project that incorporates many skills such as creativity, imagination, higher level thinking, technological capabilities and more. I know I am good at some required skills, but with others, unfortunately I am less capable."

Many of the students said that the structured support of the process provided by the lecturers played a significant role, helping them allay concerns and fears. As one of the students wrote:

"It was very hard for me to connect with virtual world but I was very comfortable to express myself because of the structured way it was taught."

Another student wrote:

"Using the software is very easy. The college's virtual world does not require much intelligence as opposed to "Second life." I understood what to do when it was first explained by the lecturer guiding us and I didn't need any further explanation. It was very convenient and easy to grasp. The instruction chart (provided by the lecturers) was very helpful and assisted our understanding of the work and the final project. At first, we did not think about all the things that appear in the table, and while filling out the table, I was able to be creative". 
This expression reflects a gradual emotional advancement in the way students related to the VR task. This was enabled by mediating the VR world and assignments through a table that students needed to fill out according to pre-specified instructions and guidance from the lecturers.

\subsection{Verbal Persuasion (Verbal Encouragements)}

Throughout the course, students were given reinforcements by their peers and lecturers. Feeling comfortable, students were provided with a positive atmosphere that enabled them to learn:

"When we received the first class assignment I had many concerns. After all, this is a learning process based on complex technology, a project that incorporates many skills such as creativity, imagination developed, higher level thinking, technological capabilities and more... We received guidance and tools such as help from lecturers, clear instructions model, group consultation and support, cooperation etc. I noted that the instructions were detailed and easy to understand. It helped replace a feeling of fear with a sense of confidence and motivation."

Also,

“... discussing with the group was fruitful and interesting. All of us helped each other. It allowed us to be focused, and contributed to our strength and personality structure. Each of us had a final framework and a clear objective, and we used each other to find the way there. Group dynamics and individual contribution of each team member is remarkable."

The concept of team work, consultation, and discussion created a dynamic that had a strong effect on the students. In one student's words:

"The thinking process took time. At first, I did not understand the assignment and what exactly was expected of me, but after consulting with my team, we were able to begin formulating ideas."

And in another student's words:

"Personally, I found this assignment more accessible, understandable, and clear worded than previous assignments. This is because the way in which instructions are detailed in the table, numbered step-by-step, greatly helped me."

As seen in student reflections, VR combined cognitive, emotional, and psychomotor skills. One could err while in the VR platform without suffering the consequences of physical ill fate. It seemed that VR allowed students to experience the needs of their peers giving them encouragement, and it supported the process by allowing them to be expressed freely.

\subsection{Vicarious Experience (Self-Modeling)}

Usually Vicarious Experience refers to the "success of the other" as perceived by the individual, serving as a motivational boost that assists in overcoming challenges. At first, the students experienced difficulties, for example:

"When the course instructor introduced the task I was very frustrated feeling I had no control; I could not cope."

However, witnessing the success of their peers helped them foster their own success:

"First, it is important to note that in this course I discovered my strengths and weaknesses. Tasks were very hard for me but I saw my friends within the group succeeding. This helped me cope with the tasks."

Their success in fulfilling the task at hand was accompanied by the social success of working in teams:

"Think about the process I went through in the course, both personally and socially. What set me is the experience of working in groups, an experience I had not done before."

\subsection{Enactive mastery (performance outcomes)}

Since success nurtures further success, it serves as one of the core requirements for developing self-efficacy. At the end of the course, students produced an "educational 3D creation," a final piece that brought about the concept of success. Students related to their experience as follows:

"First, I will say that the course "Educating for the future" required us to use all higher order thinking skills. For us, as students, this is important, necessary, useful and comprehensive. Although we experienced many difficulties, ultimately, to my great joy, I was able to overcome them and did the job the best way possible for me anyway." 
In the words of another student:

"I think VR can help students think positively and not give up. The hard work started with easy and low level requirements and gradually allowed for success and achievement. It was worth all the effort."

Besides developing and increasing their self-efficacy, success enabled students to carry over its effect and rationalize difficulties on their path to becoming future teachers. One of the students wrote the following which reflected the move from concrete mission to wider educational thought:

“... summing up my remarks and rationale, I want to convey through the VR creation that "Knowledge is power" and therefore we need to explore, to discover, and experiment with everything that goes on around us to become wiser. It is important and fitting for us to know more new and intriguing things in our lives!"

\subsection{VR Stimulates Interest and Creativity}

Student reflections showed that VR allowed them to express their creativity. The different VR experiences created thinking processes that led to producing the required 3D creation. It opened students' minds to a different mode of thinking. For example, one student reported:

"The experience required me to think more creatively. It also helped to make more novel and innovative 3D creations."

Another student wrote:

"It was very interesting to create a great $3 \mathrm{~d}$ creation of our choice. Personally, I believe that there are all kinds of different and challenging assignments that can be done with software, I was really impressed."

Students recognized that VR could assist them and their future pupils in stimulating interest and innovation:

"I think it develops different ways of thinking, and it also allows self-study after. Of course, the use of technology prepares us for the future and helps us understand the use of all kinds of important technological inventions."

Students were also able to identify unorthodox and irregular thinking patterns:

"I think the curriculum is interesting, challenging, and relevant to us as educators in the future. It teaches us to be creative and combine different teaching methods and thinking outside of the box."

\subsection{VR Promotes Social Interaction among Learners}

While working on their VR creations, students acknowledged the importance of their interactions with their peers for improving their social skills. For example, one student reported:

"I noticed that we needed group's consultation, support and cooperation. Consultation with the group was fruitful and interesting while group dynamic and individual contribution of each team member was remarkable and we enjoyed it."

Another student commented on how VR required him to put more time and effort into his interactions with others in his group:

"We needed to be creative, and this required more work and investment in others. I enjoyed working with them during our time together."

\subsection{Drawbacks of Using VR in Education}

The main difficulty encountered was that not all students felt "connected" to VR. Although not quantified, the general notion was that about half of the students felt the "wow" effect and were committed to "discovering" the new world presented to them through VR.

Another difficulty encountered was related to the technological and logistic barriers to be overcome. We used technology within our budget. The Open Simulator platform is one of the most popular platforms as it is open source and available. However, for it to serve its purpose without user frustrations (e.g. delay in online activity, etc.), bandwidth needs to be sufficiently wide and a computer with server specifications is required.

\section{Discussion and Conclusion}

The study brought to light a number of key insights. Student reflections showed a wide range of negative emotions and thoughts: fears, misunderstanding, and confusion. As the students progressed in their work on the VR platform, those feelings became more positive and empowering. Students gained a sense of self-efficacy and satisfaction with their acquisition of different and challenging tools and skills for teaching in the modern age.

Working in VR provides students with new challenges which are completely different from traditional frontal 
teaching. Presenting the challenging learning environment of VR to the student teacher demonstrates an innovative, different, and creative way. It poses challenges of active teaching and learning in which the learner becomes an active participant, creating and being creative.

In addition, we saw that the creative processes that encounter virtual reality environment have an impact on feelings and emotions in general and in particular on the sense of self-efficacy of students facing a complex challenge and unfamiliar ways of dealing with it. Thus, it presents intellectual and emotional challenges.

We propose to give VR a more prominent place in teacher training, with active experience that includes technology rich environments, the VR environment in particular, and the accompanying process of reflective thinking and collaboration in particular. This will improve student outcomes (Dorman, Fraser, Dorman, \& Fraser, 2009) allow for constructing new competencies, beliefs, and personal empowerment student aptitude important as a teacher in the future. The unique environment of the educational 3D creations allows and invites the construction of knowledge and thinking about creative action or concrete guidelines. It creates a bridge between the real world and imaginary worlds of content (real or virtual), thereby promoting the learning of the teacher, the facilitator, and the learner being a student or a student teacher.

This experience enriches students as a teaching tool in the area of advanced technology, it stimulates a wide range of emotions and feelings. Some researchers even point out that VR, using different technologies and computer simulation, represents a realistic understanding of different situations (Valentin, 2013; Wu, Lee, Chang, \& Liang, 2013). Hence, this process can change perceptions, attitudes, feelings, and emotions and provide particularly meaningful and creative learning experiences. These, in turn, empower the learner's perception of emotional space and personal capability.

We recommend seeing VR environments as a wider educational concept and not just another educational technological tool. It could be added as a new teaching module, included as an innovation unit within an existing course of training the teachers of tomorrow. In addition to developing or increasing their self-efficacy, students were able to carry over its effect to rationalize difficulties on their way to becoming future teachers. This is one of the objectives of education: the move from concrete mission to a wider educational thought.

\section{References}

Ahn, H.-S., \& Cho, Y.-M. (2015). Analysis on the Effects of the Augmented Reality-Based STEAM Program on Education (pp. 125-130). https://doi.org/10.14257/astl.2015.92.26

Bandura, A. (1982). Self-efficacy mechanism in human agency. American Psychologist, 37(2), 122-147. https://doi.org/10.1037/0003-066X.37.2.122

Bandura, A. (1995). Self-Efficacy in Changing Societies. Cambridge University Press. https://doi.org/10.1017/CBO9780511527692

Bautista, N. U., \& Boone, W. J. (2015). Exploring the Impact of TeachMETM Lab Virtual Classroom Teaching Simulation on Early Childhood Education Majors' Self-Efficacy Beliefs. Journal of Science Teacher Education, 26(3), 237-262. https://doi.org/10.1007/s10972-014-9418-8

Chen, C. J. (2006). The design, development and evaluation of a virtual reality based learning environment. Australasian Journal of Educational Technology, 22(1). https://doi.org/10.14742/ajet.1306

Cherniss, C. (2000). Emotional intelligence: What it is and why it matters. In annual meeting of the Society for Industrial and Organizational Psychology, New Orleans, LA (Vol. 15). Retrieved from http://www.talentsmart.com/media/uploads/pdfs/eq-what-it-is.pdf

Dorman, J. P., Fraser, B. J., Dorman, J. P., \& Fraser, B. J. (2009). Psychosocial Environment and Affective Outcomes in Technology-Rich Classrooms: Testing a Causal Model. Social Psychology of Education: An International Journal, 12(1), 77-99. https://doi.org/https://doi.org/10.1007/s11218-008-9069-8

Gist, M. E., \& Mitchell, T. R. (1992). Self-Efficacy: A Theoretical Analysis of Its Determinants and Malleability. Academy of Management Review, 17(2), 183-211. https://doi.org/10.5465/AMR.1992.4279530

Kim, A. J., \& Ko, E. (2012). Do social media marketing activities enhance customer equity? An empirical study of luxury fashion brand. Journal of Business Research, 65(10), 1480-1486. https://doi.org/10.1016/j.jbusres.2011.10.014

Kremenitzer, J. P., \& Miller, R. (2008). Are You a Highly Qualified, Emotionally Intelligent Early Childhood Educator? YC Young Children; Washington, 63(4), 106-108.

Lunenburg, F. C. (2011). Decision making in organizations. International Journal of Management, Business and 
Administration, 15(1), 1-9.

Miles, M. B., Huberman, A. M., \& Saldaña, J. (2013). Qualitative Data Analysis: A Methods Sourcebook (3rd ed.). Thousand Oaks, Califorinia: SAGE Publications, Inc.

Nissim, Y., Weissblueth, E., Scott-Webber, L., \& Amar, S. (2016). The Effect of a Stimulating Learning Environment on Pre-Service Teachers' Motivation and 21st Century Skills. Journal of Education and Learning, 5(3), 29-39. https://doi.org/https://doi.org/10.5539/jel.v5n3p29

Pantelidis, V. S. (2010). Reasons to use virtual reality in education and training courses and a model to determine when to use virtual reality. Themes in Science and Technology Education, 2(1-2), 59-70.

Snyder, C. R., \& Lopez, S. J. (Eds.). (2001). Handbook of Positive Psychology. Oxford England; New York: Oxford University Press.

Sutton, R. E., \& Wheatley, K. F. (2003). Teachers' Emotions and Teaching: A Review of the Literature and Directions for Future Research. Educational Psychology Review, 15(4), 327-358. https://doi.org/10.1023/A:1026131715856

Valentin, A. (2013). Motivation and Learning Strategies in the Use of ICTs among University Students. Computers \& Education, 61, 52-58. https://doi.org/10.1016/j.compedu.2012.09.008

van der Bijl, J. J., \& Shortridge-Baggett, L. M. (2001). The theory and measurement of the self-efficacy construct. Scholarly Inquiry for Nursing Practice, 15(3), 189-207.

Weissblueth, E., Nissim, Y., \& Amar, S. (2014). Educating for the Future: A Structured Course to Train Teachers for the 21st Century. Creative Education, 5(11), 900-912. https://doi.org/10.4236/ce.2014.511103

Wu, H.-K., Lee, S. W.-Y., Chang, H.-Y., \& Liang, J.-C. (2013). Current status, opportunities and challenges of augmented reality in education. Computers \& Education, 62, 41-49. https://doi.org/10.1016/j.compedu.2012.10.024

\section{Copyrights}

Copyright for this article is retained by the author(s), with first publication rights granted to the journal.

This is an open-access article distributed under the terms and conditions of the Creative Commons Attribution license (http://creativecommons.org/licenses/by/4.0/). 